\title{
Defining Smart Glasses: A Rapid Review of State-of-the-Art Perspectives and Future Challenges From a Social Sciences' Perspective
}

\author{
Niek Zuidhof ${ }^{1,3}$ (1) $\cdot$ Somaya Ben Allouch ${ }^{2} \cdot$ Oscar Peters $^{1} \cdot$ Peter-Paul Verbeek $^{3}$ \\ Received: 16 July 2021 / Revised: 15 October 2021 / Accepted: 18 October 2021 / Published online: 31 October 2021 \\ (c) The Author(s) 2021
}

\begin{abstract}
Over recent decades smart glasses have gained increased attention in both the research arena and recently also in the consumer market, even though there is not yet a clear definition of what exactly smart glasses entail and underexposed perspectives are not represented. This study used a rapid review to assess the current understanding of smart glasses with the aim of defining them. Searches were performed across six databases, followed-up by a content-based evaluation of title and abstract. A total set of 14 relevant publications was identified to help arrive at a definition and characteristics of smart glasses. As a result, it was observed in both the research literature and in the public domain that many different names are used for smart glasses, and that in some cases there is unclarity about what constitute smart glasses. Therefore, an adapted definition of smart glasses is developed based on the existing original rationale of ubiquitous computing and taking the current state-of-the-art knowledge into account. This article provides an overview of and suggestion for defining smart glasses from a social sciences' perspective to better inform researchers, developers, designers and companies who are involved in the design, development, research of smart glasses.
\end{abstract}

Keywords Definition $\cdot$ Smart glasses $\cdot$ Head-mounted displays $\cdot$ Rapid review $\cdot$ Social sciences

\section{Introduction}

Over recent decades, smart glasses have grown from a single invention to an entire research area. Although the earliest recorded mention of eye glasses is attributed to Roger Bacon in 1268, the first wearable screens appeared in the 1960s and were patented by Heilig, followed by experiments by Bell Helicopter [1] and the head-mounted three-dimensional display [2]. Twenty years later, the research area of ubiquitous computing and augmented reality started to appear around 1990 [3, 4]. Recently, with

Niek Zuidhof

e.n.zuidhof@saxion.nl

1 Saxion University of Applied Sciences, M.H. Tromplaan 28, 7513 AB Enschede, The Netherlands

2 University of Amsterdam, Spui 21, 1012 WX Amsterdam, The Netherlands

3 University of Twente, Drienerlolaan 5, 7522 NB Enschede, The Netherlands various types of smart glasses introduced over the last years such as Google Glass [5], Electrooculography glasses [6] and HoloLens [7], smart glasses became an interesting topic for designers, researchers and consumers [8]. However, with the growing interest in smart glasses, it became noticeable that the absence of a precise definition of smart glasses has led to a lack of clarity on the subject [9]. Furthermore, the growth in interest has stimulated the availability of more types and brands of smart glasses. However, it seems that challenges arise in defining smart glasses and those challenges are apparent in two ways, namely the inconsistent use of various terms to describe the same smart glasses and discussion about how to term the various types of smart glasses. First, inconsistency is observed in the various names that describe the same product. For example, smart glasses are also termed smart eye wear computing [10]. Second, a discussion about terming various kinds of smart glasses was observed. Google Glass is a famous example of a head-mounted display but is also termed a head-up display [11]; however, Google Glass might not meet the definition of a head-up display. A 
head-up display does augment additional information into reality and is commonly projected onto a windscreen. Unlike with a head-up display, Google Glass is a device that is worn near to the eye and focusing on the screen causes a blurred environment [12]. Furthermore, Google Glass has been used as an example for the definition of augmented reality smart glass (ARSG) [12, 13] but is also explained as assisted reality which might be more suitable for its capabilities [9]. Although there are reasons to term it smart glasses, the definition of augmented reality (AR) [15] is not applicable to Google Glass due to its lack of (spatial) registration in 3D or alignment with the "real" world. Other examples of ambiguity in terming smart glasses can be found in that head-worn displays were sometimes termed as optical see-through systems or video see-through modes [16]. Another example is found in the field of ubiquitous computing where Electrooculography (EOG) glasses such as Jins Meme were also specifically described as smart glasses [6]. This will also be discussed in the sections entitled "terming of smart glasses" and "definition of smart glasses." These examples support the notion that there are inconsistencies in terming smart glasses and the lack of agreement about how it differs from related concepts from the "reality-virtuality continuum" [17] and successors [9].

Although there has been an earlier attempt to define smart glasses which is: "Augmented Reality Smart Glasses (ARSGs) are defined as wearable Augmented Reality (AR) devices that are worn like regular glasses and merge virtual information with physical information in a user's view field" [18], that definition is narrow and does not comprehend the current state of the art of smart glasses in both the history of smart glasses and user-driven studies. Those studies have shown that human-technology interaction changes [19-23] and various issues such as fashion, design and ethical issues become more important [9, 23-26]. In addition, smart glasses have a history of decades, in which ubiquitous computing occupies an important place. Ubiquitous computing was in turn inspired by phenomenology and post-modernism [3], and Steve Mann described wearing computerized eyewear as a "mediated version of reality," meaning more than only augmented reality [19]. These perspectives do not resonate in current definitions.

Smart glasses are gaining momentum and have been an increasingly important topic for research in a wide range of fields, e.g., medical settings [27], social sciences [28], maintenance [29] and forensic settings [30]. Therefore, the research questions of this study are: (1) How are smart glasses currently defined in the scientific literature and (2) what are their characteristics? The overall objective is to the shed light on underexposed perspectives of smart glasses in various fields and to develop a definition which does justice to the state of the art in defining smart glasses.
Hereby, we hope to support social scientists, researchers, developers and designers involved in the development of smart glasses.

This article reviews the current state of the art regarding the definition of smart glasses, and it is structured as follows. In the first section, the multidisciplinary theoretical background is briefly discussed in terms of its history and origins in related concepts such as head-mounted displays, ubiquitous computing, AR and augmentation. Then, the essential smartness of glasses will be discussed, as well as the relationships between human and technology. Furthermore, this section explains the problem of the many names used for smart glasses more in detail. In the second section, a definition will be developed that fits in with the original rationale and the current situation of smart glasses. In the final section, key conclusions are drawn and future directions in research related to the proposed definition will be suggested.

\section{Multidisciplinary Theoretical Background: Underexposed Perspectives}

Research into smart glasses has a history spanning decades. Beginning with the birth of the first head-mounted display (HMD), further extended by the idea of augmentation, Augmented Reality and the growth of Ubiquitous Computing, this theoretical background discusses those topics in that order, followed by considering the smartness of glasses and the mediated reality of smart glasses. This theoretical background will explain how ubiquitous computing was initially influenced by philosophy and phenomenology and that both disciplines overlap in their use of certain terms such as mediated reality. For this reason, this theoretical background is also approached in a multidisciplinary way.

\section{Head-Mounted Displays}

In a broader sense, glasses that combine the digital and physical were already being mentioned in the 1960s when Ivan Sutherland talked about "the ultimate display" that could give us a chance to gain familiarity with concepts not realizable in the physical world. "It is a looking glass into a mathematical wonderland" and it could be, with suitable programming the wonderland into which Alice walked [21], p. 506]. He later presented a head-mounted threedimensional display [2] that showed transparent wire frame line drawings provided by the available computational abilities at that time.

In the research community, workshops and publications on wearable computing first appeared around the 1990s in the field of ubiquitous computing, which will be discussed 
straight after AR and augmentation have been introduced. Nowadays, smart glasses and AR are often mentioned together. However, the first international AR workshop already appeared in 1998 and the authors believed then that "Augmented Reality had become a viable, accepted and consequential human-computer interface research topic" [4], p. ix]. Today, wearable computing and AR still remain topics of interest in research and are gaining increased attention with the introduction of smart glasses for consumers. Before considering smart glasses further, AR will first be defined.

\section{Augmented Reality: Beginnings and Definition}

Although AR is nowadays classified alongside other variations of reality $[9,17]$, the development of AR started out as a subset of mixed reality [17] and the field of Virtual Environments or Virtual Reality where a user is immersed in a virtual world and cannot see the real world [4]. Although Virtual Reality is also inherent in head-mounted displays, it is applied in more distinctive devices, worn differently than eyeglasses and might also not conform to the notion of to what glasses are. In contrast, AR is a variation that allows the user to see the real world and virtual objects combined. The first publication about this concept was in the context of a pilot project in aviation. The term AR was coined by Caudell and Mizell to describe this way of information presentation [32] and was increasingly used before a formal definition of AR was proposed [22, 24-26]. AR was later specifically defined as systems that have the following three characteristics: (1) It combines the real and the virtual; (2) it is interactive in real time; and (3) it is registered in 3D [15].

\section{Augmentation: Key to the Experience of Most Smart Glasses}

A step back in history shows the use of terms such as "augmenting" and "augmentation." However, the predecessor of AR cannot be directly traced from its name. It was first termed "enhanced reality" with which researchers wanted to distinguish it from virtual reality and was originally presented as a subset of virtual reality. Enhanced reality was claimed to have great potential and the specific aim of intelligence amplification. For instance, the technology "augments the decision-making criteria of human operators by enhancing their visual perception" [24], p.61,33].

Looking at the above-described characteristics of smart glasses and the availability of the various kinds of smart glasses, it is possible to identify some smart glasses that support AR, while others do not have that functionality but do augment the real-world experience instead. The difference between AR and augmentation lies in the definition of the concepts. AR is a narrow definition which describes what the functionality means, while augmentation is a broader concept which describes how a relation between humans, technology and the world can be classified.

Both the concepts of AR and augmentation offer substantial benefits that can be helpful in defining smart glasses. Turning now to more recent literature concerning augmentation, it is important to also examine other fields related to ubiquitous computing and human-computer interaction. For example, another explanation of augmentation can be found in the Philosophy of Technology. Comparing the field of the Philosophy of Technology with Ubiquitous Computing will show that there are more similarities than one might think at first sight and which we will discuss later. Augmentation, as a broader term, is used in this specific subarea of philosophy to describe another perspective on combining the physical and the virtual worlds.

In the Philosophy of Technology, augmentation is used to describe smart glasses in terms of human-technology relationships. In such relationships, technology is seen as a mediator between humans and the world. Within that relationship, various types can be categorized and some of those apply to smart glasses. First, there is the embodiment relationship in which technologies form a unity with a human being. In the case of glasses, a user looks through the glasses rather than at the glasses. Second, the hermeneutic relationship is a relation in which human beings read how technologies represent the world, in the way that a metal detector represents the presence of metal. Here, technologies form a unity with the world that is directed to the human being. In the case of smart glasses, the embodiment and hermeneutic relationship results in a bifurcation and a fusion of the human-world relationship that is termed augmentation. For example, an embodied smart glass will give an experience of the world, and in addition, the smart glasses give a representation (hermeneutic) of the world in a parallel screen [19]. The Philosophy of Technology and Ubiquitous Computing share some basic ideas, which will become clear when the history of the smartness of glasses is discussed.

\section{History of the Smartness of Glasses}

The term "smart" implies a certain keen intelligence. Hence, smart glasses imply the same promise to amplify human intelligence, as its predecessor-enhanced realitypromised [33]. Currently, smart products are widely available and the term "smart" brings us one step back, to the beginning of what is also referred to as "calm computing." Ubiquitous computing, a term coined in 1988 by 
Mark Weiser, led to decades of research in trying to let computers be less obtrusive and more interwoven into the physical environments of people while improving humanto-human communication. Initially, in early 1988, the ubiquitous computing program had four building efforts: (1) LiveBoard, which is a large wall display; (2) ParcPad, which is a book-sized computer; and (3) ParcTab, which is a palm-sized computer. These three devices were complemented with a fourth offering: Activebadge, an infrared emitting tag that could be used for determining location, among other things. These products could, when combined with a flexible computational infrastructure, recognize a device's name, location, situation, usage, connectivity and ownership of each device. This was a new conception of what computers could be and feel like [3, 28, 29] and was the basis of the term "smart." Since then, research and products have been built upon these concepts. More recently, ubiquitous computing has been divided into three base designs: (1) smart devices that are characterized as mobile, wireless and service; (2) smart environments that consist of embedded system devices; and (3) smart interaction between devices [38]. The original underpinnings of ubiquitous computing can help to define smart glasses in the current situation since there seems to be consensus in the literature described above that smartness of smart glasses should arise from computer hardware, software, mobility, wirelessness and the ability to connect to other devices and services.

However, having briefly discussed the smartness of products, ubiquitous computing embraces more than only smart devices. In the original vision of ubiquitous computing, reference was also made to the social implications of computers. Observations made some technologists, including Mark Weiser, less consider about particular features of a computer such as specifications, but much more about the social implications such as situational use, daily activities and interaction with the physical world. The goal was calm computing, reflecting at the desired state of mind of the user. Compared with a well-balanced hammer that disappears in the hands of a carpenter and allows him or her to concentrate on the task, they hoped that computers could play their part in similar magic disappearing acts. However, they envisaged also some major challenges such as balancing between control and simplicity, between unlimited power and straightforwardness and between the seduction of smooth digital mediation and the immediacy of complex human beings [28, 31].

The relationship between human and technology was present from the beginning of the ubiquitous computing vision. Mark Weiser was inspired by his colleagues at PARC (Palo Alto Research Center, Inc.) who were social scientists, anthropologists and philosophers [40]. In a cartoon inspired by phenomenology and post-modernism,
Weiser explained the human-technology relation of ubiquitous computing, demanding that there should be no blockage between people and computers but lots of interactions between them instead [41]. And he was not the only researcher to stress that the interactions between humans and technology are important. Even before the term AR became widely used, Steve Mann had already been a longterm user of smart glasses and summarized its use as that "it provides a 'mediated' version of reality" [19]. Having introduced phenomenology and post-modernism to help gain new insights into smart glasses in this study, the final section of the theoretical background further explains these concepts of the mediating role that technology can play in the relationships between humans and the wide world.

\section{Smart Glasses and Mediated Reality}

As mentioned above, ubiquitous computing and the Philosophy of Technology have more in common and share more ideas than just augmentation. The relationship between humans and technology and mediation are two of these central topics of research in post-phenomenology which has already existed for decades.

The mediation theory in the Philosophy of Technology finds its base in the question of how human beings, technologies and the world interact with each other. In this theory, technology is seen as the mediator between human beings and the world. Reciprocal relationships between human beings, technology and the world can explain how they relate to and influence each other. As in the example which was discussed above in the "augmentation" section, smart glasses can represent a combination of mediated relationships. For instance, a user wears smart glasses and looks through the glasses so it can form a unity with the user which is termed an embodiment relationship. Second, smart glasses both represent the world to the user as an experience and add extra information in a parallel screen. This is termed a hermeneutic relationship [27, 35]. On the other hand, we saw "the world" act somewhat nervously to users with smart glasses because they were concerned about their control and privacy $[36,37]$. Thus, this example shows the various and complementary relationships between a user, technology and the world.

Furthermore, relationships in terms of mediation can also reveal both explicit and implicit capabilities of the technology. Explicit use of smart glasses is built in and meant to be used in a specific way by the designers; for example, how to receive information about the environment of the user through the smart glasses. However, implicit use was not explicitly built in and was initially more hidden-but is revealed when humans and technology relate to the world. This can be found, for example, in the ethical issues behind and social implications of smart 
glasses. Rewinding back to the original vision of ubiquitous computing, this was partly foreseen and described as a lack of control [3] but researchers had not yet worked out robust responses to these implications. The same privacy concerns also and not having an answer to that apply to Google Glass [43]. Since there remain unanswered questions about the interaction of smart glasses which can affect the wider implementation, we argue for the use of a multidisciplinary approach in early stages of research to help understand the interaction between user, technology and the world where ethical and social implications are also included [21].

\section{Terming of Smart Glasses}

Having discussed the history of smart glasses in related fields, it is also important to look at the recent terms given to smart glasses before moving to a definition. At the beginning of ubiquitous computing, various names were already being used for smart glasses such as a heads-up, see-through, head-mounted display (HUDSET) [32], seethrough HMDs with AR [45] and Digital Eye Glass and Computer-aided vision [19]. In recent research, several other terms were introduced to describe smart glasses.

Over the previous decade, and similarly to the beginning of ubiquitous computing, multiple names were still found in publications about smart glasses. For example, headworn AR and head-worn displays were sometimes termed as optical see-through systems or video see-through modes [16]. Another example is that smart eyewear was discussed as part of ubiquitous computing and Electrooculography (EOG) glasses were specifically described as smart glasses. In addition, it was also presented as a sensing device including vertical and horizontal EOG channels, accelerometer and gyroscope data [6]. In 2013, beta tests were performed with Google Glass [46] introducing a wearable device with a combination of features that puts it into a class of devices known as smart glasses [47]. Furthermore, from 2017 until recently, the term "smart glasses" became more commonly seen in research publications. "Smart-glasses, digital eye glass, eye glass display, or personal imaging systems are wearable devices that display images to the visual field of a user. They are designed to add visual elements to the visual experience of a person without significantly distorting or disturbing the person's ordinary vision, qua use, interaction with the actual world and qua experience" [16], p.702]. However, in that definition, the authors do not fully define the augmenting experience. Similarly, another attempt was made to specifically define smart glasses by including AR in the following definition: AR smart glasses or data glasses, digital eye glasses or personal imaging system, are devices that are worn like regular glasses and merge virtual and physical information in the field of view of the user [18] and sometimes in other cases, smart glasses were more broadened to include, for example, "wearable computers that add information alongside or to what wearer sees. Alternatively, smart glasses are sometimes defined as wearable computer glasses that are able to change their optical properties at runtime" [10]. To summarize, we observe that the term "smart glasses" has become a kind of an umbrella term that is still narrowly defined with a lack of clarity in describing its characteristics. Therefore, we aimed to examine the definition of smart glasses through a rapid review.

\section{Methods}

Following the recommendations made by [48], a rapid review was conducted to assess what is known about the definition of smart glasses. Falling under the umbrella of Cochrane review methods [49-51], a rapid review has been described as a method to obtain evidence through synthesis and has a shorter turnaround time than a standard systematic review. The following review questions were formulated that were based on the objectives of this study: (1) How are smart glasses currently defined in the peer-reviewed publications and (2) what are their characteristics?

\section{Search Strategy}

Searches were conducted from November 1, 2020, to December 1, 2020. The online databases such as Scopus, Web of Science, ACM Digital Library, IEEE Explore, Psyc Info, and Philosopher's Index were used. Only peer-reviewed publications written in English were considered. The final set of search key words used in the study are presented in Table 1 and were checked by an information specialist from the University of Twente. The search iteration is included in "Appendix A".

\section{Search Part I}

Databases were searched using all combinations of the search key words. All synonyms were connected with the disjunction "OR," and both topics were connected with the conjunction "AND." Unfortunately, IEEE Xplore was unable to combine search strings; therefore, we decided to narrow this search in later search phases to remain a consistent method during search part I. Keywords were searched for in title, abstract and keywords. One exception was made for the Philosopher's Index which had not the option to search for keywords; therefore, only title and abstract were searched. 
Table 1 Search key words

\begin{tabular}{ll}
\hline Definition & Smart glasses \\
\hline "Defin*" & "smart glasses" \\
AND NOT & "smartglasses" \\
"high definition" & "smart eyewear" \\
AND NOT & "smarteyewear" \\
"virtual reality" & "digital eyewear" \\
& "head mounted display" \\
& "optical head mounted display" \\
& "optical see through display" \\
& "head worn display" \\
& "computational glasses" \\
& "digital eye glass" \\
& "augmented reality (smart) glasses" \\
& "wearable augmented reality" \\
& "wearable augmented reality glasses" \\
& "mixed reality glasses" \\
& "mixed reality smart glasses" \\
& "near eye display"
\end{tabular}

\section{Selection Strategy}

Table 6 in "Appendix A" presents the number of publications for the combinations of topics for each search engine. Searches were performed for all fields and all documents. Based on search part I, we conclude that there are no specific publications in three databases available to define smart glasses. In two of the three remaining databases, the number of hits is quite high and we still have options for refining our search strategy.

\section{Search Part II}

In part I, searches gave a reasonable first impression but we were not completely satisfied with the results. We observed that although we had our search strings checked by an information specialist, we could also try a different search strategy, especially since IEEE Xplore was unable to combine our search strings. Thus, in search part II we first searched using the smart glasses search string and then searched within results for the definition search string.

When comparing search results of parts I and II, we observed differences. Scopus and Web of Science showed more hits in the search within results compared to search using Boolean operators. IEEE Explore showed fewer results than in search part I. The ACM Digital Library and the Philosopher's Index did not have the option to search within results, and therefore, the search stopped after the smart glasses search string and is noted as "-" in Table 8 in "Appendix A". In search part II, we conclude that this search strategy was only refining for IEEE Explore, not for other databases. This IEEE database was the only database in part I that was unable to combine search strings; therefore, in search part III we decided to use the search within result only for IEEE Explore, whereas we can combine search strings for the other databases.

\section{Search Part III}

Our first impression of the search results from search parts I and II was that some of the search terms were not relevant to our research question. The search word "Defin*" was intended to search for "definition" or "define," but not to find "high-definition" and "Term*" was intended to search for "terminology" or "terming" but did not satisfy in the search results because we did not want to find "terminal" in our searches. The word "describe" is often used in the abstract to explain the outline of an article but does not contribute to our search. The words "characterizing," "explaining" and "specifying" were also too broad and did not contribute to our search for specific definitions of smart glasses. In some publications, the term "smart" was added, for example, in "augmented reality smart glasses" (see "Introduction" section). Adding the term "smart" in "augmented reality glasses" did not lead to extra hits with the search string used in search part III and is therefore placed within brackets. Another observation is that we encountered many publications about virtual reality in the screening after search part II. As we explain in our introduction, although virtual reality devices are also headmounted displays, these devices are more distinguishable from other smart glasses because of the closure of the physical world and therefore might not adhere to a definition of glasses. Therefore, we formulated a new search string in search part III (Table 1), and this resulted in less hits, as given in Table 2 .

Searching and reviewing the selected articles was conducted by two researchers. Each reviewer decided whether smart glasses were defined, or aimed to be defined in the publication, whether in the title or abstract. Publications that passed the screening were included, but duplicates were removed. The results of this screening are given in "Appendix A". After the first screening, 20 publications were selected to search for the definition and characteristics of smart glasses; see the flowchart in Fig. 1. Table 3 presents the definition and characteristics of smart glasses found in the selected publications $(n=14)$.

\section{Results}

Having identified publications that define smart glasses ( $n=14)$, the terming and characteristics of smart glasses in the publications will be discussed more in the following. 
Table 2 Number of hits per combination of topics per database

\begin{tabular}{|c|c|c|c|c|c|c|}
\hline & Scopus & $\begin{array}{l}\text { Web } \\
\text { of } \\
\text { science }\end{array}$ & $\begin{array}{l}\text { ACM digital library-ACM } \\
\text { guide to computing } \\
\text { literature }\end{array}$ & $\begin{array}{l}\text { IEEE xplore } \\
\text { digital library } \\
\text { Search within } \\
\text { results of smart } \\
\text { glasses }\end{array}$ & $\begin{array}{l}\text { Psyc } \\
\text { info }\end{array}$ & $\begin{array}{l}\text { Philosopher's } \\
\text { index }\end{array}$ \\
\hline $\begin{array}{l}\text { Smart } \\
\text { glasses and } \\
\text { definition }\end{array}$ & 131 & 1 & 0 & 16 & 0 & 0 \\
\hline
\end{tabular}

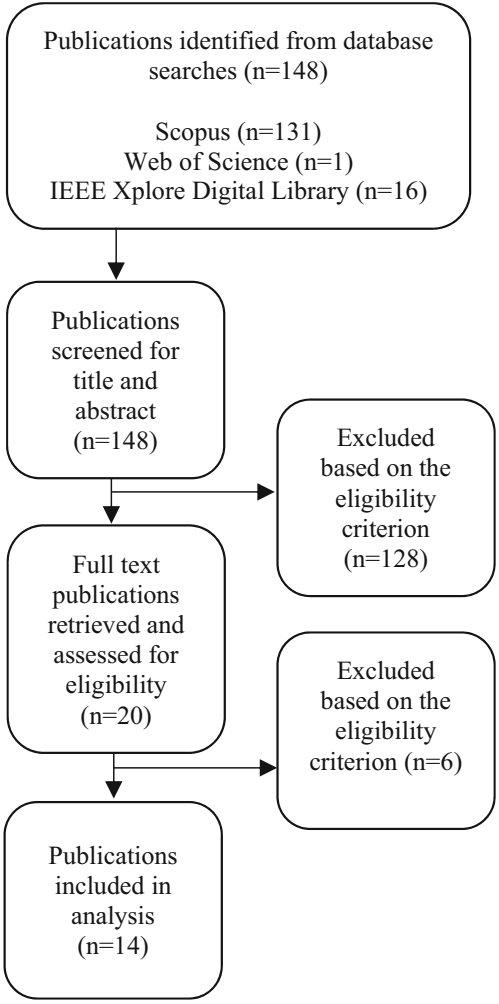

Fig. 1 Selection procedure search part III

First, aiming at finding commonalities to contribute to a definition for smart glasses, the various terms used for smart glasses were counted as frequencies and the characteristics expressed in Table 3 were counted once per publication. Eight publications presented head-mounted displays and four publications termed those smart glasses. Near-eye displays were presented in two publications, and smart eyewear was mentioned in one publication. Thus, the term "head-mounted displays" is the most common; however, this is still a broad category that includes various kinds of head-mounted displays such as both VR and AR and not just wearable see-through displays. Counting the characteristics of smart glasses in Table 3 gave us the word "display" 12 times and "wearable" 7 times, followed by "device" (5), AR (5), computer (4) and pervasive (2), see Table 4. From this, we conclude that display and wearability are important characteristics, but that does not take us much further to answer our quest for distinctive characteristics or in forming a robust definition of smart glasses.

Second, aiming to find distinctive features for smart glasses, a thematic analysis [64] was conducted to find themes other than the found frequencies from the descriptions of smart glasses in Table 3. The analysis was done separately by two coders with an intercoder agreement of $78,6 \%$. The themes were listed and categorized, as given in Table 5 .

Instead of looking for commonalities (Table 4), Table 5 lists key words derived from the search results and represents a different insight compared to that obtained from counting matches. Furthermore, they can be assembled into a paragraph, and below, we will elaborate on these themes.

The themes and key words from Table 5 can be summarized as follows: Having much in common with ubiquitous computing and wearable technology, ultraportable handsfree devices that might be binocular or monocular are worn close to the body and are termed (optical) head-mounted displays, near-eye displays or smart glasses. They are computerized and contain a small transparent or opaque display, video camera and voice recorder and have input hardware for manual entry or gestures. They might use optical lens projection or retinal projection to deliver (spatial) augmented reality or virtual reality. They can display or overlay various kinds of information in the user's (peripheral) field of view of the external environment giving a pervasive experience. Also, it can detect events and body movements and communicate with IT environments using Bluetooth or Wi-Fi. They could be worn all day and are always operational. There are various markets such as consumer markets for gaming or social applications, but also for defence, hardware and content, engineering, law enforcement, firefighting and medical applications. For example, smart glasses were used in intraoperative clinical settings for the purpose of specific diagnoses and developing detailed plans. There is a higher need for privacy and a high chance of interrupting the user; however, such devices have the potential to revolutionize health care, reshape how we work and may pave the way for new approaches.

The summary of key words from the search results brings us one step closer to a robust definition of smart 
Table 3 Results of search part III

\begin{tabular}{lll}
\hline Reference Title Description of smart glasses & D
\end{tabular}

[52] Defining requirements for an Augmented Reality system to overcome the challenges of creating and using design representations in co-design sessions

Retinal image quality in near-eye pupil-steered systems

[46] A new tool in medicine Properties of a peripheral head-mounted display

Toward a characterization of human activities using smart devices: a micro/macro approach

Seeing twenty-first century data bleed through the fifteenth century wound man

Additional visualization via smart glasses improves accuracy of wire insertion in fracture surgery

Wearable technology in the operating room: a systematic review

See through optical architectures for wearable displays
The two most common approaches within AR are the use of an optical Head-Mounted Display or a handheld device, which can overlay digital content on the user's field of view. Spatial Augmented Reality is less common and projected onto the surface of a physical object

AR's most defining characteristic is the facility to overlay virtual objects on a real environment. The most suitable devices for AR are Head Mounted Displays. They allow a deeper immersion level, thereby facilitating more specific diagnoses and detailed plans. HMDs can reshape the way clinics work and pave the way for radically new approaches

The near-eye display is the primary interface for virtual reality and augmented reality. The added requirement for AR is optical see-through display architectures that support a large field of view and high resolution while keeping visibility of the external world, all within the form of a wearable that could be worn all day

Wearable technology is defined as smart watch, smart wristband, or smart eyewear

Smart glasses are a wearable device and contains a small computer built into a head-mounted monitor. It can display various kinds of information as a kind of augmented reality and may include a video camera. The most well-known brand is Google Glass

Wearable technology has the potential to revolutionize healthcare. Wearable technologies found in the systematic review were Google Glass, GoPro or customised headmounted displays (HMDs) in a wide range of intraoperative clinical settings

Smart glasses are ultra-portable devices that interact with body movements and the IT environment. In the field of research and in terms of functionality, they have much in common with ubiquitous computing. They can detect events, can be both precise and permanently operational

Smart glasses are defined as a hands-free computerized communicator (via Bluetooth or Wi-Fi) with a transparent screen for viewing text and images, a video camera, a voice recorder/transmitter and a voice input interface and is wearable as a pair of glasses

Head-mounted displays are based on either one of two techniques: optical lens projection and retinal projection. Another way to differentiate HMDs is to determine whether an image is monocular of binocular. The display can be opaque or transparent, with mirror-projection or image recorded with a video camera in front. A peripheral head-mounted display is a visual display mounted to the head that is in the peripheral field of view of the user

In defence applications, there are head up displays and helmetmounted displays; in the consumer market head mounted displays. There are various markets offering their specific functionalities, hardware and content for near-to-eye displays, social smart glasses, gaming headsets, professional HMDs (engineering and technical), specialized HMDs (medical, law enforcement, firefighting) and the defence market 
Table 3 (continued)

\begin{tabular}{|c|c|c|}
\hline Reference & Title & Description of smart glasses \\
\hline [60] & Wearable systems for healthcare applications & $\begin{array}{l}\text { Wearable systems are mobile electronic devices that can be } \\
\text { unobtrusively embedded in the user's outfit. They range from } \\
\text { micro sensors in clothes, computerized watches to belt-worn } \\
\text { PCs with a head-mounted display }\end{array}$ \\
\hline [61] & $\begin{array}{l}\text { The control unit for a head-mounted operating microscope used } \\
\text { for augmented reality visualization in computer-aided surgery }\end{array}$ & $\begin{array}{l}\text { There are two main types of head-mounted displays for } \\
\text { augmented reality: the optical and video see-through type. } \\
\text { Augmented reality involves the overlay of computer-generated } \\
\text { graphics }\end{array}$ \\
\hline [62] & User-defined game input for smart glasses in public space & $\begin{array}{l}\text { Smart glasses such as Google Glass are always-available } \\
\text { displays and could offer a pervasive gaming experience }\end{array}$ \\
\hline [63] & $\begin{array}{l}\text { Heat is in the eye of the beholder: towards a better authenticating } \\
\text { on smartglasses }\end{array}$ & $\begin{array}{l}\text { Smartglasses are wearables that are becoming worn closer to the } \\
\text { body of the user and may have the ability to sense and record } \\
\text { activities of the user. The closer it becomes, the higher the } \\
\text { need for privacy. Smartglasses provide a small display, } \\
\text { minimal manual entry and voice- and gesture-based } \\
\text { interactions which need to be limited for technical efficiency } \\
\text { and social acceptance. Smartglasses have a high probability of } \\
\text { interrupting the user }\end{array}$ \\
\hline
\end{tabular}

Table 4 Commonalities of various terms and characteristics for smart glasses

\begin{tabular}{ll}
\hline Terms used for smart glasses & Frequency \\
\hline Head-mounted display/monitor & 8 \\
Smart glasses & 4 \\
Near-eye display & 2 \\
Smart eyewear & 1 \\
\hline Characteristics of smart glasses & Frequency \\
\hline Display & 12 \\
Wearable & 7 \\
AR & 5 \\
Device & 5 \\
Computer & 4 \\
Pervasive & 2
\end{tabular}

glasses. The categories presented in Table 5 show that there are many different characteristics to smart glasses. However, it also becomes clear that outliers in the key words influence the summary described above; for example, some publications were broad in describing headmounted displays focusing on both AR and VR. We perceive VR devices as more distinctive and not as smart glasses as we explain in our introduction. Virtual reality headsets are body worn and head-mounted but are not worn like eyeglasses and might adhere to general ideas of glasses because of the closure of the physical world. Thus, the summary above is a broad description of head-mounted displays. In the following paragraph, more focus is applied to the definition of smart glasses by using the results of the rapid review.

\section{Definition of Smart Glasses}

To our knowledge, the first attempt made by others to define the concept of smart glasses with an augmenting experience contained the following: "we develop the following definition of Augmented Reality Smart Glasses (synonym: data glasses, digital eye glasses, or personal imaging system): Augmented Reality Smart Glasses are defined as wearable Augmented Reality (AR) devices that are worn like regular glasses and merge virtual information with physical information in a user's view field" [17], p.172]. Now, based on our review, we have seen that we need to update that definition. That definition of Augmented Reality Smart Glasses might be too narrow since we also found other characteristics of smart glasses across various publications describing smart glasses, such as projection methods, collect user data and implications of use (Table 3). Furthermore, this definition seems to have two limitations. First, the authors have not treated AR much in detail. AR was defined earlier [15] and involves more than merging virtual with physical information in the field of view of the user. Second, the key problem with that definition lies in its explanation and examples given in the publication that create confusion about the precise understanding of what smart glasses entail. Google Glass is used as an example for Augmented Reality Smart Glass [14, 18]. The HoloLens, for example, indeed meets the definition of AR; however, in contrast, Google Glass lacks tracking of 
Table 5 Key words derived from the search results

\begin{tabular}{|c|c|}
\hline Theme & Key words derived from descriptions in Table 3 \\
\hline Background & Ubiquitous computing, wearable, wearable technology, wearable device \\
\hline Portability & Ultra-portable, handsfree, mobile \\
\hline Worn & Unobtrusively embedded, pair of glasses (binocular), monocular, closer to the body, head-mounted, near to the eye \\
\hline Termed & $\begin{array}{l}\text { Optical head-mounted display, head-mounted displays, near-eye display, optical see-through display, smart eyewear, } \\
\text { smart glasses, Google Glass }\end{array}$ \\
\hline Hardware & $\begin{array}{l}\text { Small computer, belt-worn PCs, computerized, small display, transparent screen, opaque screen, video camera, voice } \\
\text { recorder/transmitter }\end{array}$ \\
\hline Interaction by & Voice input interface, manual entry input, gesture-based interactions \\
\hline Projection & Optical lens projection, retinal projection, augmented reality, spatial augmented reality, virtual reality \\
\hline Where & Field of view, peripheral field of view, real environment, external world \\
\hline Key characteristic & Display, view, overlay \\
\hline $\begin{array}{l}\text { Other } \\
\text { characteristics }\end{array}$ & Detect events and body movements, sense and record activities of the user \\
\hline Content & Digital content, virtual objects, various kinds of information, text and images, computer-generated graphics \\
\hline Experience & Immersive experience, pervasive experience \\
\hline Communication & IT environments, Bluetooth, Wi-Fi \\
\hline $\begin{array}{l}\text { Availability to the } \\
\text { user }\end{array}$ & Worn all day, permanently operational, always available \\
\hline Markets & Defence, consumer, hardware and content, social, gaming, engineering, law enforcement, firefighting, medical \\
\hline $\begin{array}{l}\text { Example of } \\
\text { application }\end{array}$ & Intraoperative clinical settings, specific diagnoses, detailed plans \\
\hline Risks & Higher need for privacy, high chance of interrupting the user \\
\hline Implications & Revolutionize healthcare, reshape work, pave the way, new approach \\
\hline
\end{tabular}

six degrees of freedom and (spatial) registration in 3D. Hence, it seems that Google Glass cannot be classified as an AR device according to the definition of Augmented Reality [14]. However, Google Glass can be classified as smart glasses or a head-mounted display [65] and still offer an augmenting experience.

In addition, there is more to add about defining smart glasses such as taking into account a broader definition of smart glasses in which a central element is the interaction between the user, technology and world itself (Table 3). The main challenges regarding the definitions of smart glasses lie within two other aspects. First, only a few of the currently available smart glasses use AR. Some only make use of sensors or 2D overlays. Smart glasses are of several types that have common characteristics such as the headmounted aspect and the interaction methods [9, 66]. Second, with respect to the original vision of ubiquitous computing, smart glasses are not only a combination of technical components, but also affect our view of the world both literally and figuratively and vice versa, that of the world on the user. The relationships mentioned above between humans and technology are important too and should also be taken into account.

Building upon the previous attempts to define and classify smart glasses and the characteristics found in this study, we present an adapted definition of smart glasses that is based on the underlying principles of ubiquitous computing and human-computer interaction and emphasizes four aspects. First, what distinguishes smart glasses from other wearable computer devices? Second, what distinguishes smart glasses from ordinary glasses? Third, what are the capabilities of the smart glasses? and fourth, the implicit and explicit meanings resulting from the use of smart glasses for individuals and society. With this in mind and the theoretical background taken into account, we developed to the following adapted definition:

Smart glasses have various characteristics and have been defined in many ways in the literature. However, based on the results described above we propose that when defining smart glasses, it must meet the following core characteristics: 
1. Head-mounted and, in most cases, worn like eyeglasses;

2. Computerized devices with user inputs and sensors, some allow hands-free use, are connected to (individually or in any combination of) the Internet (of Things), services and other remote devices, and might be supported by Artificial Intelligence;

3. May collect information from the user and his or her environment and may provide information back to the user through the glasses in an augmenting experience (display/overlay) or forwarded to another connected device. The user experience is centered around using information and communication technology without being cut off from the outside world compared to VR; and

4. Smart glasses are not just a wearable technical product. The use of smart glasses changes humans' use of information and communication of the physical and digital world. In addition, it mediates our relations with each other, our surroundings and technology differently, and it might change our values and our (technology) behavior.

Following the developments in ubiquitous computing from its beginning, the proposed adapted definition takes into account the hardware, software, connectivity, humantechnology, human-to-human interaction and its implications which does justice to the original vision of ubiquitous computing and relates to the current state-of-the-art knowledge about smart glasses.

\section{Conclusion}

\section{Main Conclusion}

This study has argued that there was a lack of clarity about what characterizes smart glasses. The overall objective was to the shed light on underexposed perspectives of smart glasses in various fields and develop a definition which does justice to the state of the art of defining smart glasses. Therefore, we observed that there are many fields involved and we went back to the origins of smart glasses and reviewed definitions of smart glasses. Those definitions were narrowly defined and that does not justice to other relevant knowledge about smart glasses. For example, the mediated reality of smart glasses has implications for our relation with each other and technology. The findings of the rapid review were transformed to commonalities by adding frequencies and distinctive characteristics based on a thematic analysis. Based on the results, we developed an adapted definition based on the existing literature.
Overall, this study strengthens the original vision of ubiquitous computing [36, 40] looking back to the historical development of smart glasses and adds to the rapidly evolving and expanding field of smart glasses. The smartness of the ever-evolving glasses was discussed to show that there is an important link with philosophy and phenomenology in the original vision of ubiquitous computing and that resulted in a renewed focus on mediated reality through the use of smart glasses which does more justice to the state of the art than the previous definitions of smart glasses.

This rapid review has firstly shown that current definitions of smart glasses were diverse and narrowly defined. The second finding to emerge from this rapid review for defining smart glasses is that the search for common characteristics only yields general aspects such as "display," "wearable" and "device." The third and most apparent finding is that distinctive characteristics of smart glasses showed the diversity in characteristics of smart glasses not only in hardware and software but also in markets, use, risks and both social and societal implications. Fourthly, taking the history of multidisciplinary fields related to smart glasses and the results of the rapid review into account, we formulated an adapted definition of smart glasses, which is described in "Results" section.

The definition of smart glasses we proposed in the results section is based on four characteristics. First, how smart glasses can be distinguished from other wearable computers. Second, how smart glasses can be distinguished from ordinary glasses. Third, what a user can do with smart glasses. Next, what is the explicit and implicit impact of smart glasses on the user and its environment? A multidisciplinary approach is needed to understand how they change our use and understanding of information and communication in the physical and digital worlds. Finally, to understand how they mediate our relations with each other, our surroundings and technology, as well as our values and our (technology) behavior. The proposed definition does more justice to relevant publications in this area and can help to interpret smart glasses, speak the same language and provide a starting point for research and projects in which multiple fields are recognized.

\section{Limitations}

The first limitation of the rapid review conducted in this study is that not all publications can be found by systematically searching for two reasons. The first reason is that we searched for only English-language peer-reviewed publications in selected databases and we might have missed other relevant publications in other languages. The 
second reason is that the search terms from our search string were not always included in key words and abstracts of the publications searched. For example, the introduction section and theoretical background of this study describe also publications that were not found by the rapid review method. We checked this several times by adjusting our search terms and assessing some publications outside the rapid review. We noticed that it happens that a publication has not included "definition" in the key words, nor it was termed "definition" in the abstract and then it will not be found by a search engine with the used search string. We have applied the rapid review method as reliably as possible and acknowledge that this might have consequences for the results found. However, we still have included those publications in the introduction section and theoretical background if they were relevant for the objective of this study. Furthermore, we developed the definition based on our results from the rapid review, but also on the state of the art with which we do justice to all relevant and available publications. Despite this limitation, the study also shows that definitions of current smart glasses are sometimes not easy to find and this work aimed to improve that situation by systematic research.

Second, smart glasses are of course also technical products. On the one hand, this study was limited by the absence of a technical description in, for example, display qualities, due to the already available suggestions in the literature and the rapid developments and aging of technology [37]; on the other hand, it was the objective to shed light on the underexposed perspectives and focus on social sciences as we also explain in our recommendations for future research.

\section{Future Directions}

Recent suggestions regarding technical developments in this field are widely available [67-69], as well as interaction suggestions $[66,70]$. Following our definition of smart glasses, we believe it is important to focus future research not only on technical aspects such as machine learning, signal processing, data and knowledge representation and information visualization [71], but equally on social aspects since we showed in our review that smart glasses also entail, for example, risks and implementation challenges and thus also touch upon multidisciplinary fields such as philosophy, psychology, communication science and human-computer interaction. This emerging field of smart glasses poses many interesting questions regarding the appropriation of smart glasses [65], adoption [72], daily use and long-term use [21] including an understanding of the mediated reality of smart glasses.

In conclusion, early on the founding fathers of ubiquitous computing stated "we have much to learn about how to make good use of this new ability" [31] and that ability referred to head-mounted displays. In addition, they came to realize with their first "ubi-comp" system that they were "in fact, actually redefining the entire relationship of humans, work and technology for the post-PC era" [36]. Regarding the diverse reactions people had to the use of mediated reality (e.g., Google Glass use) in public [44, 73], we still have to learn a lot about this research topic. And that may have become even more relevant, since with the introduction of various smart glasses it has been shown that such devices redefine our information and communication use, our relations with each other and technology, our values and our (technology) behavior. Based on the results of this, we argue for a deeper understanding of humantechnology relationships regarding smart glasses from a multidisciplinary perspective, combining the fields of human-computer interaction, philosophy, psychology and communication.

\section{Appendix A}

See Tables 6, 7, 8, 9, 10, 11 .

Table 6 Search part I: key words

\begin{tabular}{ll}
\hline Definition & Smart Glasses \\
\hline "Defin*" & "smart glasses" \\
"Term*" & "smartglasses" \\
"Descri*" & "smart eyewear" \\
"Characteri*" & "smarteyewear" \\
"Expla* & "digital eyewear" \\
"Specif* & "head mounted display" \\
& "optical head mounted display" \\
& "optical see through display" \\
& "head worn display" \\
& "computational glasses" \\
& "digital eye glass" \\
& "augmented reality glasses" \\
& "wearable augmented reality" \\
& "wearable augmented reality glasses" \\
& "mixed reality glasses" \\
& "mixed reality smart glasses" \\
& "near eye display"
\end{tabular}


Table 7 Search part I: number of hits per combination of topics per database

\begin{tabular}{lllllll}
\hline & Scopus & $\begin{array}{l}\text { Web of } \\
\text { science }\end{array}$ & $\begin{array}{l}\text { ACM digital library-ACM guide to } \\
\text { computing literature }\end{array}$ & $\begin{array}{l}\text { IEEE xplore digital } \\
\text { library }\end{array}$ & $\begin{array}{l}\text { Psyc } \\
\text { info }\end{array}$ & $\begin{array}{l}\text { Philosopher's } \\
\text { index }\end{array}$ \\
\hline Definition & $20,697,816$ & 142,757 & 1220 & 73 & $1,545,275$ & 43,489 \\
Smart glasses & 8098 & 310 & 0 & 4682 & 29 & 0 \\
$\begin{array}{l}\text { Definition and smart } \\
\text { glasses }\end{array}$ & 2337 & 2 & & $1,543,497$ & 0 & 0 \\
\hline
\end{tabular}

Table 8 Search part II: number of hits per combination of topics per database

\begin{tabular}{|c|c|c|c|c|c|c|}
\hline & Scopus & $\begin{array}{l}\text { Web of } \\
\text { science }\end{array}$ & $\begin{array}{l}\text { ACM digital library-ACM guide to } \\
\text { computing literature }\end{array}$ & $\begin{array}{l}\text { IEEE xplore digital } \\
\text { library }\end{array}$ & $\begin{array}{l}\text { Psyc } \\
\text { info }\end{array}$ & $\begin{array}{l}\text { Philosopher's } \\
\text { index }\end{array}$ \\
\hline Smart glasses & 8098 & 310 & 73 & 4682 & 29 & 0 \\
\hline $\begin{array}{l}\text { Definition (search within } \\
\text { results) }\end{array}$ & 3829 & 85 & - & 1450 & - & 0 \\
\hline
\end{tabular}

Table 9 Screening of search results Scopus in search part III

\begin{tabular}{|c|c|c|c|}
\hline & Reference & Title & Relevant quotes \\
\hline 1 & {$[52]$} & $\begin{array}{l}\text { Defining requirements for an Augmented Reality system to } \\
\text { overcome the challenges of creating and using design } \\
\text { representations in co-design sessions }\end{array}$ & $\begin{array}{l}\text { "This study captures the challenges practitioners face in } \\
\text { creating and using design representations for co-design } \\
\text { sessions and goes on to investigate the potential of Spatial } \\
\text { Augmented Reality (SAR) to overcome those challenges" }\end{array}$ \\
\hline 2 & [74] & $\begin{array}{l}\text { The Development of Augmented Reality Applications for } \\
\text { Chemistry Learning }\end{array}$ & $\begin{array}{l}\text { "This chapter describes the use of Augmented Reality (AR) } \\
\text { technology in chemistry education. The chapter begins } \\
\text { with definition analysis, development, component, working } \\
\text { principles, steps in making AR media, and supporting } \\
\text { applications that are related with AR in education } \\
\text { particularly for chemistry teaching and learning process" }\end{array}$ \\
\hline 3 & [75] & Foveated displays: Toward classification of the emerging field & $\begin{array}{l}\text { "There is not yet consensus in the field on what constitutes a } \\
\text { "foveated display." We propose a compromise between the } \\
\text { perspectives of rendering, imaging, physiology and vision } \\
\text { science that defines a foveated display as a display designed } \\
\text { to function in the context of user gaze. } \\
\text { This definition enables us to describe } 2 \text { axes of foveation, } \\
\text { gaze interaction and resolution distribution, which we then } \\
\text { subdivide to provide useful categories for classification " }\end{array}$ \\
\hline 4 & [76] & SIG: Spatiality of augmented reality user interfaces & $\begin{array}{l}\text { "First, we aim to critically discuss the definition of Spatial } \\
\text { Interfaces and outline the common components that build } \\
\text { such interfaces in today's world. Second, we would like the } \\
\text { community to reflect on the path ahead and focus on the } \\
\text { potential of what kind of experiences can Spatial Interfaces } \\
\text { achieve today" }\end{array}$ \\
\hline 5 & {$[53]$} & $\begin{array}{l}\text { An augmented reality approach to visualize biomedical } \\
\text { images }\end{array}$ & $\begin{array}{l}\text { "The most defining characteristic of AR consists of the } \\
\text { possibility to overlap virtual object to be projected by a } \\
\text { dedicated device upon a real environment. Throughout this } \\
\text { work, the development of an application for the } \\
\text { visualization of medical data in AR environments will be } \\
\text { discussed. Nowadays, the most appropriate devices for such } \\
\text { applications are Head Mounted Displays (HMDs)" }\end{array}$ \\
\hline 6 & {$[54]$} & Retinal image quality in near-eye pupil-steered systems & $\begin{array}{l}\text { "State-of-the-art near-eye displays often compromise on eye } \\
\text { box size to maintain a wide field of view, necessitating a } \\
\text { means for steering the eye box to maintain alignment with a } \\
\text { moving eye. The design space of such pupil-steered systems } \\
\text { is not well defined and the implications of imperfect steering } \\
\text { on the perceived image are not well understood" }\end{array}$ \\
\hline
\end{tabular}


Table 9 (continued)

Reference Title

7 [55] Seeing 21st Century Data Bleed through the 15th Century Wound Man

8

[56] Additional Visualization via Smart Glasses Improves Accuracy of Wire Insertion in Fracture Surgery

$9 \quad[57]$

Wearable technology in the operating room: A systematic review

Toward a characterization of human activities using smart devices: A micro/macro approach

11 [46] Smart Glasses-A New Tool in Medicine

$12[12]$ Properties of a peripheral head-mounted display (PHMD)
See through optical architectures for wearable displays
Relevant quotes

"Much of this growth is expected to come from young adult sectors; according to the Global Web Index, 71 percent of those ages 16 to 24 want "wearable tech," defined as a smart watch, smart wristband, or smart eyewear. Nearly two-thirds of global Internet users have worn a piece of technology already or are eager to do so in the future [3]"

"Smart glasses (SG) are a wearable device consisting of a small computer built into a head-mounted monitor (HMM) that can display various kinds of information"

"These articles predominantly described the use of Google Glass, GoPro or customized head-mounted

displays (HMDs) in a wide range of intraoperative clinical settings. The included articles were categorised based on the highlighted areas of clinical impact, with the majority (56) discussing various applications for enhancing intraoperative safety and efficiency. Almost all articles cited technological limitations and privacy concerns as serious barriers to the implementation of wearable technology in the operating room"

"Taking different approaches and perspectives, we use in this paper smartwatches and smartglasses to explore these behaviors and show that these objects, considered by many as gadgets, have an important role to play in understanding the lives of individuals. The main objective of this work is to introduce two new scales of activity detection, which lacks a formal and consistent definition in the literature"

"Smart glasses, defined as a computerized communicator with a transparent screen and a video camera, wearable as a pair of glasses, have started to be tested for a variety of health related applications"

"In this paper we propose a definition for Peripheral HeadMounted Display (PHMD) for Near Field Displays. This paper introduces a taxonomy for head-mounted displays that is based on the property of its functionality and the ability of our human eye to perceive peripheral information, instead of being technology-dependent. The aim of this paper is to help designers to understand the perception of the human eye, as well as to discuss the factors one needs to take into consideration when designing visual interfaces for PHMDs. We envision this term to help classifying devices such as Google Glass, which are often misclassified as a Head-Up Display (HUD) following NASA's definition"

"But recently, major companies have launched consumer compelling head mounted display solutions integrating both hardware, operating system as well as content, unlocking the decade long consumer HMD status-quo. As a result, we are witnessing today a fragmentation of the HMD market into various categories which have their very own specificity in terms of functionality, hardware and content. Such fragmentation is responsible for defining new distinct market segments such as consumer near to eye displays, social smart glasses, gaming headsets, as well as professional (engineering and technical) HMDs, specialized (medical, law enforcement, firefighting) HMDs and of course the previously existing defense market. We will be reviewing the different type of optical hardware used in such devices" 
Table 9 (continued)

\begin{tabular}{|c|c|c|c|}
\hline & Reference & Title & Relevant quotes \\
\hline 14 & {$[77]$} & Head-worn displays for NextGen & $\begin{array}{l}\text { "HWDs with an integrated head-tracking system are being } \\
\text { researched as they offer significant potential benefit under } \\
\text { emerging NextGen operational concepts. Two areas of } \\
\text { benefit for NextGen are defined" }\end{array}$ \\
\hline 15 & [78] & $\begin{array}{l}\text { Helmet-mounted display requirements: Just another HUD or a } \\
\text { different animal altogether? }\end{array}$ & $\begin{array}{l}\text { "Other issues are unique to the head-mounted display: symbol } \\
\text { stabilization, inadequate definitions, undefined symbol drive } \\
\text { laws, helmet considerations, and field-of-view (FOV) vs. } \\
\text { resolution tradeoff requirements" }\end{array}$ \\
\hline 16 & {$[60]$} & Wearable systems for health care applications & $\begin{array}{l}\text { "Objectives: Wearable systems can be broadly defined as } \\
\text { mobile electronic devices that can be unobtrusively } \\
\text { embedded in the user's outfit as part of the clothing or an } \\
\text { accessory. In particular, unlike conventional mobile } \\
\text { systems, they can be operational and accessed without or } \\
\text { with very little hindrance to user activity. To this end they } \\
\text { are able to model and recognize user activity, state, and the } \\
\text { surrounding situation: a property, referred to as context } \\
\text { sensitivity. Wearable systems range from micro sensors } \\
\text { seamlessly integrated in textiles through consumer } \\
\text { electronics embedded in fashionable clothes and } \\
\text { computerized watches to belt worn PCs with a head } \\
\text { mounted display. The wearable computing concept is part of } \\
\text { a broader framework of ubiquitous computing that aims at } \\
\text { invisibly enhancing our environment with smart electronic } \\
\text { devices. The goal of the paper is to provide a brood } \\
\text { overview of wearable technology and its implications for } \\
\text { health related applications. Methods. We begin by } \\
\text { summarizing the vision behind wearable computing. We } \\
\text { then describe a framework for wearable computing } \\
\text { architecture and the main technological aspects. Finally we } \\
\text { show how specific properties of wearable systems can be } \\
\text { used in different health related application domains" }\end{array}$ \\
\hline 17 & {$[61]$} & $\begin{array}{l}\text { The control unit for a head mounted operating microscope } \\
\text { used for augmented reality visualization in computer aided } \\
\text { surgery }\end{array}$ & $\begin{array}{l}\text { "Two main concepts of head mounted displays (HMD) for } \\
\text { augmented reality (AR) visualization exist, the optical and } \\
\text { video-see through type" }\end{array}$ \\
\hline
\end{tabular}

Table 10 Screening of search results Web of Science in search part III

\begin{tabular}{llll}
\hline & Reference & Title & Main findings \\
\hline 18 & {$[62]$} & $\begin{array}{l}\text { User- defined game input for smart } \\
\text { glasses in Public Space }\end{array}$ & $\begin{array}{l}\text { "Smart glasses, such as Google Glass, provide always-available displays not offered } \\
\text { by console and mobile gaming devices, and could potentially offer a pervasive } \\
\text { gaming experience" }\end{array}$ \\
\hline
\end{tabular}

Table 11 Screening of search results IEEE Xplore in search part III

\begin{tabular}{|c|c|c|c|}
\hline & Reference & Title & Main findings \\
\hline 19 & [63] & $\begin{array}{l}\text { Heat is in the eye of the beholder: Towards } \\
\text { better authenticating on smartglasses }\end{array}$ & $\begin{array}{l}\text { "Smart and wearable devices are trendy electronic objects that have become } \\
\text { increasingly popular in recent years. Those devices are, by definition, tightly } \\
\text { connected with the user's personal activities. Authentication is therefore a } \\
\text { critical feature for both identifying users and personalizing the services on the } \\
\text { device. In particular, the emergence of smartglasses changed the way we } \\
\text { thought a wearable could assist users in their daily activities." }\end{array}$ \\
\hline 20 & [79] & $\begin{array}{l}\text { Irrigation and Soil Moisture Detection by } \\
\text { Using Augumented Reality (sic) }\end{array}$ & $\begin{array}{l}\text { "augmented reality is the upcoming technology in the modern world. It is } \\
\text { defined as the combination of appearance of } 3 \mathrm{~d} \text { figure of real and virtual } \\
\text { objects, interaction with real time appearance and the projection of real and } \\
\text { virtual images." }\end{array}$ \\
\hline
\end{tabular}


Funding No funding was received for conducting this study.

\section{Declarations}

Conflict of interest The authors have no relevant financial or nonfinancial interest to disclose.

Open Access This article is licensed under a Creative Commons Attribution 4.0 International License, which permits use, sharing, adaptation, distribution and reproduction in any medium or format, as long as you give appropriate credit to the original author(s) and the source, provide a link to the Creative Commons licence, and indicate if changes were made. The images or other third party material in this article are included in the article's Creative Commons licence, unless indicated otherwise in a credit line to the material. If material is not included in the article's Creative Commons licence and your intended use is not permitted by statutory regulation or exceeds the permitted use, you will need to obtain permission directly from the copyright holder. To view a copy of this licence, visit http://creativecommons. org/licenses/by/4.0/.

\section{References}

1. Rhodes B A brief history of wearable computing. https://www. media.mit.edu/wearables/lizzy/timeline.html\#1966b. Accessed 11 Jan 2021

2. Sutherland I (1968) A head-mounted three dimensional display. In: Proceedings of AFIPS fall joint computer conference. pp 757-764. Thompson Books, Washington

3. Weiser M (1991) The computer in the 21st century. Sci Am Spec Issue Commun Comput Netw, pp 78-89

4. Behringer R, Klinker G, Mizell DW (1999) Augmented reality: placing artificial object in real scenes. Peters, A.K./CRC Press

5. Google (2014) Explorers. https://sites.google.com/site/glass comms/glass-explorers

6. Ishimaru S, Uema Y, Kunze K, et al (2014) Smarter eyewearusing commercial EOG glasses for activity recognition. In: UbiComp 2014 - Adjun Proceedings of the 2014 ACM International Journal Conference Pervasive Ubiquitous Computing Doi: https://doi.org/10.1145/2638728.2638795

7. Microsoft (2018) Why Hololens. https://www.microsoft.com/nl$\mathrm{nl} /$ hololens/why-hololens

8. Digi-Capital (2019) Apple \#3 in smartglasses with no product. https://www.digi-capital.com/news/2019/05/apple-3-in-smart glasses-with-no-product/. Accessed 4 Jun 2019

9. Dwivedi YK, Ismagilova E, Hughes DL et al (2021) Setting the future of digital and social media marketing research: Perspectives and research propositions. Int J Inf Manage 59:102168. https://doi.org/10.1016/j.ijinfomgt.2020.102168

10. Singh ED, Pathak R, Singh S (2019) Smart Glass. Ijarcce 8:9-13. https://doi.org/10.17148/ijarcce.2019.8502

11. Starner T (2013) Project glass: an extension of the self. IEEE Pervasive Comput 12:14-16. https://doi.org/10.1109/MPRV. 2013.35

12. Matthies DJC, Haescher M, Alm R, Urban B (2015) Properties of a peripheral head-mounted display (PHMD). Commun Comput Inf Sci 528:208-213. https://doi.org/10.1007/978-3-319-213804_37

13. Greenemeier L (2013) The future of smart glasses. Sci Am 309:21. https://doi.org/10.1038/scientificamerican0713-21
14. Rauschnabel PA, Brem A, Ro YK (2015) Augmented reality smart glasses: definition, conceptual insights, and managerial importance. 1-21

15. Azuma RT (1997) A survey of augmented reality. Presence Teleoperators Virtual Environ 6(4):355-385. https://doi.org/10. 1016/j.dss.2003.08.004

16. Kruijff E, Swan JE, Feiner S (2010) Perceptual issues in augmented reality revisited. In: 9th IEEE international symposium on mixed and augmented reality 2010 science and technology ISMAR 2010 - Proceedings. pp 3-12. https://doi.org/10.1109/ ISMAR.2010.5643530

17. Milgram P, Kishino F (1994) A taxonomy of mixed reality visual displays. IECIC Trans Inf Syst E77-D:1-15

18. Ro YK, Brem A, Rauschnabel PA (2018) Augmented reality smart glasses: definition, concepts and impact on firm value creation. Augmented reality and virtual reality. Springer International Publishing, Berlin, pp 169-181

19. Mann S (2013) What I've learned from 35 years of wearing computerized eyewear. IEEE Spectr, pp 42-47

20. Verbeek P-P (2015) Beyond Interaction: a short introduction to mediation theory. Interact ACM. https://doi.org/10.1145/2751314

21. Zuidhof N, Ben Allouch S, Peters O, Verbeek PP (2019) A theoretical framework to study long-term use of smart eyewear. In: UbiComp/ISWC 2019-Adjunct proceedings of the 2019 ACM international joint conference on pervasive and ubiquitous computing and proceedings of the 2019 ACM international symposium on wearable computers. pp 667-670

22. Zuidhof N, Ben Allouch S, Peters O, Verbeek PP (2019) Anticipated acceptance of head mounted displays: a content analysis of youtube comments. In: 2019 IEEE international conference on pervasive computing and communications workshops, PerCom Workshops 2019. pp 399-402

23. Zuidhof N, Ben Allouch S, Peters O, Verbeek P-P (2021) Perspectives on the adoption and mediation implications of smart glasses: a qualitative focus group study in healthcare. submitted

24. Hofmann B, Haustein D, Landeweerd L (2017) Smart-glasses: exposing and elucidating the ethical issues. Sci Eng Ethics 23:701-721. https://doi.org/10.1007/s11948-016-9792-z

25. Rauschnabel PA (2018) Virtually enhancing the real world with holograms: An exploration of expected gratifications of using augmented reality smart glasses. Psychol Mark 35:557-572. https://doi.org/10.1002/mar.21106

26. Chuah SH-W (2019) Why and who will adopt extended reality technology? Literature review, synthesis, and future research agenda. SSRN Electron J. https://doi.org/10.2139/ssrn.3300469

27. Dougherty B, Badawy SM (2017) Using google glass in nonsurgical medical settings: systematic review. JMIR mHealth uHealth 5:e159. https://doi.org/10.2196/mhealth.8671

28. Keshav NU, Salisbury JP, Vahabzadeh A, Sahin NT (2017) Social communication coaching smartglasses: well tolerated in a diverse sample of children and adults with autism. JMIR mHealth uHealth 5:e140. https://doi.org/10.2196/mhealth.8534

29. Russel J (2017) Chinese police are using smart glasses to identify potential suspects. https://techcrunch.com/2018/02/08/chinesepolice-are-getting-smart-glasses/?guccounter=1

30. Karabiyik U (2015) Building an intelligent assistant for digital forensics. Florida State Univ Coll Arts Sci. https://doi.org/10. 13140/RG.2.1.1620.2727

31. Sutherland IE (1965) The ultimate display. Proc IFIP Congr, pp 506-508

32. Caudell TP, Mizell DW (1992) Augmented reality: an application of heads-up display technology to manual manufacturing processes. In: Proceedings of the twenty-fifth hawaii international conference on system sciences. IEEE, vol 2, pp 659-669 
33. Bowskill J, Downie J (1995) Extending the capabilities of the human visual system. ACM SIGGRAPH Comput Graph 29:61-65. https://doi.org/10.1145/204362.204378

34. Caudell TP (1994) Introduction to augmented reality. SPIE Proc Telemanipulator Telepresence Technol 2351:272-281

35. Drascic D (1993) Stereoscopic vision and augmented reality. Sci Comput Autom 9:31-34

36. Weiser M, Gold R, Brown JS (1999) The origins of ubiquitous computing research at PARC in the late 1980s. IBM Syst J 38:693-696. https://doi.org/10.1147/sj.384.0693

37. Crabtree IB, Rhodes BJ (1998) Wearable computing and the remembrance agent. BT Technol J 16:118-124. https://doi.org/ 10.1023/A:1009642301754

38. Poslad S (2009) Ubiquitous Computing. John Wiley and Sons, Ltd, Chichester

39. Weiser M (1988) Ubiquitous computing. https://web.archive.org/ web/20050204163428/http://www.ubiq.com/hypertext/weiser/ UbiHome.html. Accessed 24 Mar 2020

40. Weiser M (1995) The technologist's responsibilities and social change. Comput Commun Mag 2:17

41. Weiser M Phenomenological post-modernism explained and related to computer science, in cartoons. https://web.archive.org/ web/20160828204425/http://www.ubiq.com/hypertext/weiser/Per sonWorldDistinction4Up.gif. Accessed 24 Mar 2020

42. Verbeek P-P (2014) Op de vleugels van Icarus. Hoe techniek en moraal met elkaar meebewegen. Lemniscaat, Rotterdam

43. Hong J (2013) Considering privacy issues in the context of Google glass. Commun ACM 56:10-11. https://doi.org/10.1145/ 2524713.2524717

44. Honan M (2013) I, glasshole: my year with google glass. https:// www.wired.com/2013/12/glasshole/. Accessed 24 Mar 2020

45. Azuma R, Bishop G (1994) Improving static and dynamic registration in an optical see-through HMD. In: Proceedings of the 21st Annual Conference on Computer Graphics Interactive Techniques SIGGRAPH. https://doi.org/10.1145/192161.192199

46. Klein GO, Singh K, Von Heideken J (2015) Smart glasses-a new tool in medicine. In: Studies in health technology and informatics. p 901. IOS Press, Amsterdam

47. Singh K, Klein GO (2014) Google glass has potential for rheumatology, orthopedic surgery. In: Rheumatol

48. Ganann R, Ciliska D, Thomas H (2010) Implementation science open access methodology expediting systematic reviews: methods and implications of rapid reviews

49. Moher D, Stewart L, Shekelle P (2015) All in the family: systematic reviews, rapid reviews, scoping reviews, realist reviews, and more. Syst Rev 4:1-2. https://doi.org/10.1186/s13643-0150163-7

50. Garritty C, Stevens A, Gartlehner G et al (2016) Cochrane rapid reviews methods group to play a leading role in guiding the production of informed high-quality, timely research evidence syntheses. Syst Rev 5:1-5. https://doi.org/10.1186/s13643-0160360-z

51. Tricco AC, Antony J, Zarin W et al (2015) A scoping review of rapid review methods. BMC Med. https://doi.org/10.1186/ s12916-015-0465-6

52. O'Hare J, Dekoninck E, Mombeshora M et al (2020) Defining requirements for an augmented reality system to overcome the challenges of creating and using design representations in codesign sessions. CoDesign 16:111-134. https://doi.org/10.1080/ 15710882.2018.1546319

53. Bergonzi L, Colombo G, Redaelli DF, Lorusso M (2019) An augmented reality approach to visualize biomedical images. Comput Aided Des Appl 16:1195-1208. https://doi.org/10. 14733/cadaps.2019.1195-1208
54. Ratnam K, Konrad R, Lanman D, Zannoli M (2019) Retinal image quality in near-eye pupil-steered systems. Opt Express 27:38289. https://doi.org/10.1364/oe.27.038289

55. Stevens N, Wernimont J (2018) Seeing 21st century data bleed through the 15th century wound man. IEEE Technol Soc Mag 37:46-54. https://doi.org/10.1109/MTS.2018.2876214

56. Tsubosaka M, Hiranaka T, Okimura K et al (2017) Additional visualization via smart glasses improves accuracy of wire insertion in fracture surgery. Surg Innov 24:611-615. https://doi.org/ $10.1177 / 1553350617735950$

57. Kolodzey L, Grantcharov PD, Rivas H et al (2017) Wearable technology in the operating room: a systematic review. BMJ Innov 3:55-63. https://doi.org/10.1136/bmjinnov-2016-000133

58. Faye S, Louveton N, Gheorghe G, Engel T (2016) Toward a characterization of human activities using smart devices: A micro/macro approach. In: Proceedings of the IEEE INFOCOM, pp 676-681. Doi: https://doi.org/10.1109/INFCOMW.2016. 7562162

59. Kress B (2014) See through optical architectures for wearable displays. In: Imaging and applied optics 2014. OSA, Washington, p JTu1A.1

60. Lukowicz P, Kirstein T, Tröster G (2004) Wearable systems for health care applications. Methods Inf Med 43:232-238. https:// doi.org/10.1055/s-0038-1633863

61. Figl M, Birkfellner W, Ede C, et al (2002) The control unit for a head mounted operating microscope used for augmented reality visualization in computer aided surgery. In: Proceedings of the international symposium mix augment reality, ISMAR 2002, pp 69-75. https://doi.org/10.1109/ISMAR.2002.1115075

62. Tung Y-C, Hsu C-Y, Wang H-Y, et al (2015) User-defined game input for smart glasses in public space. In: Proceedings of the 33rd Annual ACM conference on human factors in computing systems. pp 3327-3336. ACM, New York

63. Gheorghe G, Louveton N, Martin B, et al (2016) Heat is in the eye of the beholder: Towards better authenticating on smartglasses. In: Proceedings of the 2016 9th Interantional Conference on Human System Interact HSI 2016, pp 490-496. Doi: https:// doi.org/10.1109/HSI.2016.7529679

64. Braun V, Clarke V (2006) Using thematic analysis in psychology. Qual Res Psychol 3:77-101. https://doi.org/10.1191/ 1478088706qp063oa

65. Zuidhof N, Ben Allouch S, Peters O, Verbeek P-P (2018) Appropriation of wearable augmented reality. In: Proceedings of the 20th International Conference on Human-Computer Interact with Mob Devices Serv Adjun - MobileHCI '18, pp 437-439. Doi: https://doi.org/10.1145/3236112.3236182

66. Lee LH, Hui P (2018) Interaction methods for smart glasses: a survey. IEEE Access 6:28712-28732. https://doi.org/10.1109/ ACCESS.2018.2831081

67. Kim K, Billinghurst M, Bruder G et al (2018) Revisiting trends in augmented reality research: a review of the 2nd Decade of ISMAR (2008-2017). IEEE Trans Vis Comput Graph 24:2947-2962. https://doi.org/10.1109/TVCG.2018.2868591

68. Wang X, Ong SK, Nee AYC (2016) A comprehensive survey of augmented reality assembly research. Adv Manuf 4:1-22. https:// doi.org/10.1007/s40436-015-0131-4

69. Koulieris GA, Akşit K, Stengel M et al (2019) Near-eye display and tracking technologies for virtual and augmented reality. Comput Graph Forum 38:493-519. https://doi.org/10.1111/cgf. 13654

70. Miller MR, Jun H, Herrera F et al (2019) Social interaction in augmented reality. PLoS ONE 14:e0216290. https://doi.org/10. 1371/journal.pone. 0216290

71. IoWT (2016) Internet of wearable things. https://sites.google com/site/iowt2016/ 
72. Masood T, Egger J (2020) Adopting augmented reality in the age of industrial digitalisation. Comput Ind. https://doi.org/10.1016/j. compind.2019.07.002

73. Lapowsky I (2014) Google's new fashion-savvy exec can't fix glass' biggest flaw. https://www.wired.com/2014/05/glass-ivyross/. Accessed 24 Mar 2020

74. Irwansyah FS, Nur Asyiah E, Maylawati DS et al (2020) The development of augmented reality applications for chemistry learning. Springer International Publishing, Berlin

75. Spjut J, Boudaoud B (2019) Foveated displays: Toward classification of the emerging field. ACM SIGGRAPH 2019 Talks. SIGGRAPH 2019:1-2. https://doi.org/10.1145/3306307.3328145

76. Vovk A, Wild F, Rodrigues DG, Weibel N (2019) SIG: spatiality of augmented reality user interfaces. In: Conference on Human Factors in Computing Systems- Proceedings, pp 2-5. https://doi. org/10.1145/3290607.3311756
77. Bailey RE, Shelton KJ, Arthur JJ III (2011) Head-worn displays for NextGen. Head- Helmet-Mounted Displays XVI Des Appl 8041:80410G. https://doi.org/10.1117/12.885847

78. Newman RL, Haworth LA (1994) Helmet-mounted display requirements: just another head-up display (HUD) or a different animal altogether? Helmet- Head-Mounted Displays Symb Des Requir 2218:226-237. https://doi.org/10.1117/12.177365

79. Rajkumar S, Sedhuraman K, Muruganandhan D, Harikumar A (2020) Irrigation and soil moisture detection by using augumented reality. pp 1-5. https://doi.org/10.1109/icscan49426. 2020.9262334

Publisher's Note Springer Nature remains neutral with regard to jurisdictional claims in published maps and institutional affiliations. 